\title{
Religião, Saúde e Cura: um Estudo entre Neopentecostais ${ }^{1}$
}

\author{
Religion, health and cure: a study among neopentecostalians
}

Elder Cerqueira-Santos

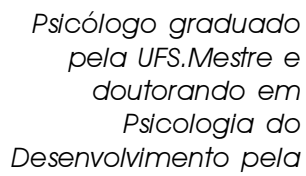

\section{Sílvia Helena Koller}

Professora do Curso de Pós-Graduação em Psicologia do Desenvolvimento UFRGS, psicóloga, Doutora em Educação pela PUCRS.

\section{Maria Teresa Lisboa Nobre Pereira}

Professora do Departamento de Psicologia da UFS psicóloga, doutoranda em Sociologia pela UFCE.

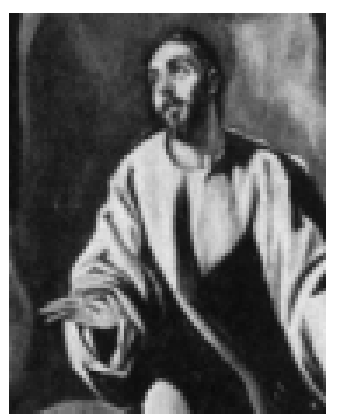

Resumo: O sistema de saúde precário tem levado grande parte da população à procura de formas alternativas para o restabelecimento do seu bem-estar. Buscamos entender como se dá a construção das noções de saúde e doença a partir de uma visão religiosa do mundo e quais as influências dessa concepção na relação dos pacientes com a Medicina ou com a busca de poderes sobrenaturais. Participando de seis cultos de uma igreja neopentecostal, observamos e realizamos entrevistas semi-estruturadas com três fiéis e um pastor. Percebemos que o discurso da igreja fornece sentido, orienta e ajuda as pessoas a resolverem e contornarem suas aflições cotidianas. O "diabo" torna-se a causa principal de todos os males. Assim, a doença passa a ser uma ação demoníaca e a cura requer o exorcismo do fiel. Destaca-se que os rituais de cura da igreja e a consulta médica são atos quase excludentes.

Palavras-Chave: Religião, saúde, cura milagrosa.

Abstract: The precarious health system has taken great part of the population to search alternative forms for the re-establishment of his/her well-being. We sought to understand the way he/she feels the construction of the notions of health and disease starting from a religious vision of the world and with the influences of this conception in the patients' relationship with Medicine or with the search for supernatural powers. Participating in six cults of a neopentecostal church, we observed and accomplished semi-structured interviews with three followers and a shepherd. We noticed that the speech of the church supplies sense, guides and helps the people to solve problems and outline their daily afflictions. The "devil" becomes the main cause of all evils. Thus the disease becomes a demoniac action and the cure requests the exorcism of the faithful. It stands out that the rituals of cure in the church and the medical consultation are almost excluding actions.

Key Words: Religion, health, miraculous cure.

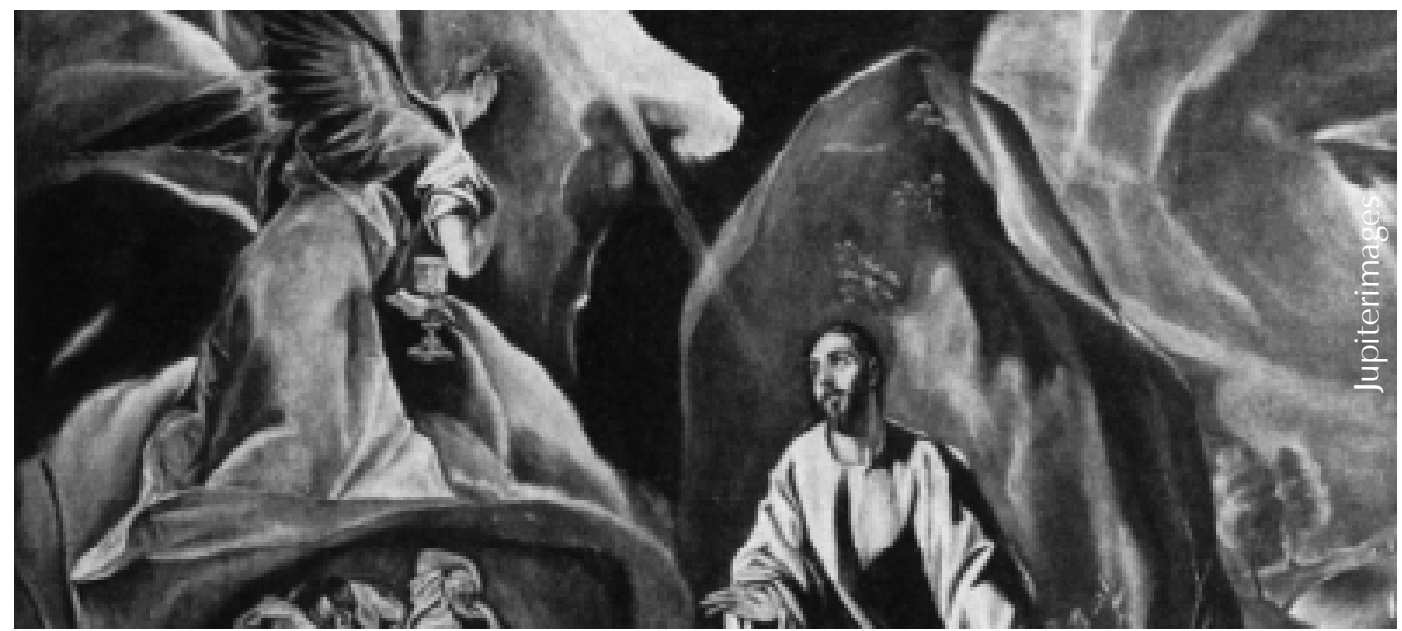

Nos últimos tempos, temos assistido a um grande aumento do número de novas religiões e de correntes esotéricas em todo o mundo, inclusive no Brasil. Esse fato pode ser o reflexo das demandas crescentes geradas pelas pessoas em seu cotidiano, bem como da busca de sentidos para a vida em um mundo tão dinâmico e instável. Enquanto a ciência avança com novas descobertas tecnológicas e teorias revolucionárias, parte da população se volta para o divino, o mágico, à procura das soluções ou de respostas para o significado de estar no mundo. Para Pereira (1997), o movimento de busca do "religioso" pode ser, também, uma tentativa de tentar entender, intervir e controlar o presente e o futuro.

A religião expressa uma busca de vinculação da pessoa ao divino. A palavra religião vem do latim: religio, formada pelo prefixo re (outra vez, de novo) e o verbo ligare (ligar, unir, vincular). Para Alves (1979), a religião é um fenômeno social que se organiza em função de símbolos sagrados. Gaarder 
(2000), em uma revisão da literatura, apresenta dois conceitos complementares de religião. $\mathrm{O}$ primeiro sustenta que a religião significa a relação entre o homem e o poder sobre-humano no qual ele acredita ou do qual ele se sente dependente. Essa relação expressa-se através de emoções especiais (confiança, medo), conceitos (crenças) e ações (culto e ética) (Tiele, s.d., citado por Gaarder, 2000). O outro conceito é de Glasenapp (s.d.), que considera a religião como a convicção de que existem poderes transcendentes, pessoais ou impessoais, que atuam no mundo e se expressam por insight, pensamento, sentimento, intenção e ação (em Gaarder, 2000).

Acreditamos que é nesse contexto de possibilidade de contato com o sobrenatural que as pessoas se dirigem aos templos, principalmente àqueles que prometem, através da intercessão do divino, a resolução dos problemas dos seus seguidores. Nesse sentido, um grupo particular e que vem destacando-se por sua expansão e atuação é a igreja neo-pentecostal. Estas são igrejas dissidentes de outros grupos evangélicos que surgiram nas últimas duas ou três décadas, como a Igreja Universal do Reino de Deus, Igreja Renascer em Cristo, Igreja Jardim de Deus no Brasil, Igreja Casa da Bênção e outras dezenas (Guareschi, 1995). Tais igrejas apresentam-se como um mundo que acolhe e protege, oferecendo o que as pessoas procuram na religião: atendimento das necessidades, sentido para a vida e controle do presente e do futuro. Essas igrejas vêm atuando, consideravelmente, no campo da saúde. Prometem curas e amparo emocional, assim como interferem na maneira como os fiéis encaram, elaboram e aceitam esse fato.

O fiel transforma-se, assim, em cliente da igreja, em um consumidor à procura de bens e serviços oferecidos por essas instituições, especialmente no caso da resolução de problemas de saúde, cuja situação é agravada por um sistema de saúde ineficiente e desacolhedor. Para Concone (1987), quando a Medicina não mostra uma saída que agrade ao ser humano, ele tenta outro caminho.

Para os fiéis, principalmente os das igrejas neopentecostais, que são basicamente pessoas de nível socioeconômico baixo e pouca escolaridade (Prandi, 1997), é fácil aceitar a característica mágica da cura nas igrejas, pois já há uma visão mitológica do serviço médico. Com sua onipotência, os médicos agem, para eles, como magos conhecedores de porções mágicas que curam ou aliviam sintomas (vacinas, pomadas, gotinhas etc.). Para essas pessoas, um composto químico elaborado e estudado por grandes laboratórios são gotinhas que "o doutor mandou tomar", assim como o pastor que manda tomar água do rio
Jordão, o padre que benze com água benta ou o médium que fluidifica água. Segundo Alves (1979), o mundo tecnológico que não dá explicações acessíveis para essas pessoas torna-os habitantes de um mundo mágico, no qual a falta de entendimento científico da Medicina pode ter a mesma lógica dos tratamentos alternativos.

Para Bourdieu (1987), está acontecendo atualmente uma redefinição da divisão corpo e alma e, conseqüentemente, da divisão relativa ao trabalho de cura das almas e do corpo. Falar do corpo pode ser também a maneira de falar da alma. Segundo Bourdieu (1987), os próprios nãoreligiosos cedem, com freqüência, à tentação de transformar saberes positivos em discursos normativos, capazes de exercer uma forma de terrorismo legitimado pela ciência.

Diante do panorama apresentado, destaca-se a adesão dos fiéis aos serviços oferecidos pelas igrejas com objetivos terapêuticos, como as sessões de cura. Tal fenômeno nos faz refletir sobre como as noções de normal e patológico atuam na ideologia dessas igrejas e seus fiéis, colaborando para o sucesso das práticas "mágicas" oferecidas.

Para Lévi-Strauss (1970), não há razão para duvidar da eficácia de certas práticas mágicas, pois a eficácia da magia implica a crença na magia; crença por parte de quem a pratica (feiticeiro/pastor), por parte do doente (fiel) e por parte do consenso (igreja, comunidade ou grupo cultural). Laplantine (1995) sugere que toda técnica também tem uma dimensão ritual, e os rituais podem conter, em si mesmos, uma eficácia propriamente terapêutica. Segundo Fish (1988), a potência da cura está na própria fé, e não em Deus. Portanto, a atuação dos curadores (pastores) seria idêntica à sugestão dada por um médico que prescreve um placebo (substância na qual os pacientes acreditam haver potência para curá-los de suas enfermidades, mas, quimicamente, não passível de comprovação).

Segundo Quintana (1999), a causa das curas religiosas pode ser explicada como o de um processo muito semelhante ao da Psicanálise. A benzedeira, a exemplo do terapeuta, oferece a seu paciente uma explicação consistente com as suas crenças. Ao atribuir a causa de um resfriado constante ou da perda do emprego a um "mauolhado", o que faz é dar ao cliente a possibilidade de lutar contra um inimigo definido, no qual ele acredita. "Ao dizer que há inveja sobre o cliente, a benzedeira o integra em uma história que torna sua situação compreensível dentro da sua ótica" (Revista Isto É, 1997, ed. eletrônica). Tais explicações, no entanto, nem sempre são assimiladas pelo cliente, mas podem gerar novas crenças, através de formas diferentes de
1 Este artigo é parte do trabalho monográfico de conclusão do Curso de Graduação em Psicologia do primeiro autor orientado pela última autora. Foi ampliado e rediscutido, fazendo parte dos estudos de pós-graduação, sob a orientação da segunda autora. 
entendimento dos seus problemas, que respondem à sua busca de sentido. Assim, tanto a interpretação de conteúdos inconscientes por parte do psicanalista como a explicação sobrenatural da benzedeira podem fazer sentido, mesmo sem se adequar às crenças preexistentes da pessoa em questão.

Segundo Neves (1984), as curas sobrenaturais só podem ser entendidas enquanto atos ritualizados, que expressam a relação dos homens com o mundo por eles sobrenaturalizado ou com os poderes que atribuem às divindades. Tais curas têm um caráter de medicina popular ou passam a ter que suportar expectativas de ocorrências espetaculares ou de mudanças não explicadas em nível racional: os milagres, o que, de certa forma, passa a ser um consenso e é corroborado pela divulgação nos órgãos de imprensa. Estes notificam como espetáculos os acontecimentos "milagreiros" e legitimam padroeiros e santuários que oferecem tais serviços sacralizados.

"... de que a medicina popular consiste em um certo número de práticas de prevenção e de cura fundadas em uma visão coerente do ser humano e do cosmos, presentes não só nas sociedades agrárias, mas em sociedades "tecnificadas" como a nossa."

Laplantine e Rabeyron
Convêm, aqui, ressaltar a idéia de Laplantine e Rabeyron (1991) de que a medicina popular consiste em um certo número de práticas de prevenção e de cura fundadas em uma visão coerente do ser humano e do cosmos, presentes não só nas sociedades agrárias, mas em sociedades "tecnificadas" como a nossa. O que ele caracteriza como uma visão mágica do mundo, para nós, pode ser simplesmente uma visão propiciadora de um sentido.

A especialização da medicina científica aponta para um caráter de fragmentação e afastamento de uma concepção mais integrada do homem, em referência ao caráter totalizante dos sistemas de representações sociais que orientam as práticas curativas não-científicas ou populares (Neves, 1984). A relação médico-paciente põe em destaque a assimetria dessa relação, a oferta de informações descontextualizadas e a posição submissa, por isso mesmo angustiante, enfrentada pelo usuário, o que também pode ocorrer na relação pastor-fiel. Quanto maior a distância social entre médico e paciente, menos este tem capacidade de contra-argumentar ou de impor outros discursos sobre saúde, doença e outros meios de tratamento. Para Boltanski (s.d., citado por Neves, 1984), o médico procura, no seu discurso, preservar o monopólio do seu saber e a autoridade que a sociedade lhe outorga para dispor da doença, e até mesmo do corpo do doente.

Porém, alguns médicos, especialmente católicos, parecem resguardar certo espaço para a divindade explicar o que eles não podem, quando nomeiam que as práticas médicas apelam para a religião é aquela em que há fracassos médicos ou morte, colocando a "vontade de Deus" como causa dos fatos, o que, de certa forma, conforta os médicos e os familiares. A religião surge, então, como resposta à necessidade de explicar e justificar fatos naturais e não-controláveis como a morte, e, às vezes, a doença. É feito um apelo a explicações religiosas, o que mostra que, mesmo orientados por um "saber científico", este não é suficiente quando transcende o humano.

Dessa forma, é aberta uma lacuna para aqueles que oferecem uma "medicina" popular fundada em práticas religiosas, como é o caso das igrejas neopentecostais, enfatizando a correlação entre suas práticas e o discurso da medicina científica. Um exemplo é o conceito de doença psicossomática difundido entre fiéis da Igreja Universal: "Psicossomática é o que o médico não cura". Essa afirmação revela uma interpenetração do saber científico no popular e vice-versa, o que, mais uma vez, aponta para a importância da investigação da influência de práticas religiosas na construção das noções de saúde, doença e cura e no modo como estas interferem na busca de tratamentos.

Para Houtart (1994), a religião faz parte das representações que os seres humanos fazem do seu mundo e de si mesmos. As pessoas constroem uma realidade que é perpassada por suas crenças religiosas, ou seja, é realizado um trabalho intelectual sobre a realidade para interpretá-la, trabalho esse que é permeado pelas condições concretas e históricas dos atores sociais. Dessa forma, as igrejas também se apropriam de conceitos de doença, saúde, normal e patológico.

Canguilhem (1979) afirmou que: "o normal não é uma média correlativa a um conceito social, não é um julgamento de realidade, é um julgamento de valor, é uma noção-limite que define o máximo de capacidade de um ser. Não há limite superior de normalidade" (p. 90). Sendo o normal considerado um julgamento de valor, entendemos ser necessária uma compreensão de como esse valor, ou esses valores, são formados, uma vez que os sujeitos que fazem tal julgamento o produzem contextualizados socio-historicamente.

A idéia de normal utilizada por Canguilhem (1979) associa o termo à normatividade. A diferença entre o estado normal e o patológico não deriva de uma variação estatística e, portanto quantitativa, como propunha Durkheim (s.d.), mas de uma variação qualitativa, na qual normal e patológico são estados diferentes. O normal implica a capacidade de instituir e de transitar entre várias normas, num movimento que oscila entre ir e vir, enquanto o como padroeiros (Neves, 1984). Outra ocasião em 
patológico se refere à incapacidade de flexibilização das normas e à conseqüente fixação em uma única norma. Desse ponto de vista, normal refere-se a um estado superior, e patológico, a um estado inferior, não do ponto de vista valorativo, como melhor ou pior, bom ou mau, mas no sentido plástico, de possibilidades de flexibilização. $\bigcirc$ homem normal é, portanto, o ser normativo, capaz de instituir novas normas, tanto orgânicas quanto sociais.

Canguilhem (1979) entende por normativo qualquer julgamento que aprecie ou qualifique um fato em relação a uma norma, mas essa norma está subordinada, efetivamente, àquele que a institui. Desse modo, podemos considerar que a relativização da normalidade pode dar-se num nível individual, pois, como nos diz Canguilhem (1979), não existe uma normalidade, e, sim, distintas normalidades, já que são os doentes que julgam - de pontos de vista muito variados - se não são mais normais ou se voltaram a sê-lo. A influência dos contextos, nesses casos, como o cultural e socioeconômico, ocorre em nível individual.

Destacamos a idéia de Canguilhem (1979) de que, para o homem que imagina o seu futuro com base na sua experiência passada, "voltar ao seu normal" significa retomar uma atividade interrompida. Curar, então, seria "fazer voltar à norma uma função ou um organismo que dela se tinha afastado" (p. 84). Portanto, mais do que a opinião do médico é a apreciação do paciente e das idéias dominantes do meio social que determina o que se chama doença.

Para Coelho e Almeida (1999), Canguilhem (1979) não opõe, desse modo, o normal ao patológico, já que este também teria uma normatividade, uma vez que a experiência de estar vivo inclui a doença. Assim, ser normal não implica necessariamente a cura de uma patologia. Sentir-se normal passa a ser, também, uma experiência individual. Para Canguilhem, o ser humano faz a sua dor e a sua doença, julgando se estas deixaram de ser normais ou se voltaram a sê-lo. Então, cura não implica saúde, necessariamente, mas pode significar um novo modo de vida instaurado pela doença. Poderíamos dizer que ela pode ser a instauração de uma nova norma que se adequou ao estado atual.

Ampliando a visão de Canguilhem (1979), Foucault (1979) também aponta a relatividade do termo normal, que pode ser observada na história da Medicina, quando, fundada na nova ordem econômica capitalista, após a Revolução Francesa, a Medicina adota uma nova postura normativa, visando ao rendimento para o bom funcionamento da engrenagem social. Foucault propõe um olhar para a doença como um produto não só biológico, mas histórico, cultural e social. De acordo com Foucault, as concepções de saúde refletem os valores sociais dominantes da cultura e da época. Com base nessa discussão, este trabalho descreve uma pesquisa etnográfica feita na cidade de Aracaju, Sergipe. Os dados foram coletados durante o ano 2000 pelo primeiro autor. Nessa época, havia na cidade uma certa "explosão", em termos de divulgação televisiva, de cultos que prometiam a cura de doenças não tratadas ou diagnosticadas pela Medicina. Uma motivação a mais para tal investigação deu-se pelo fato de o nome dos cultos ser "Sessão Psicossomática".

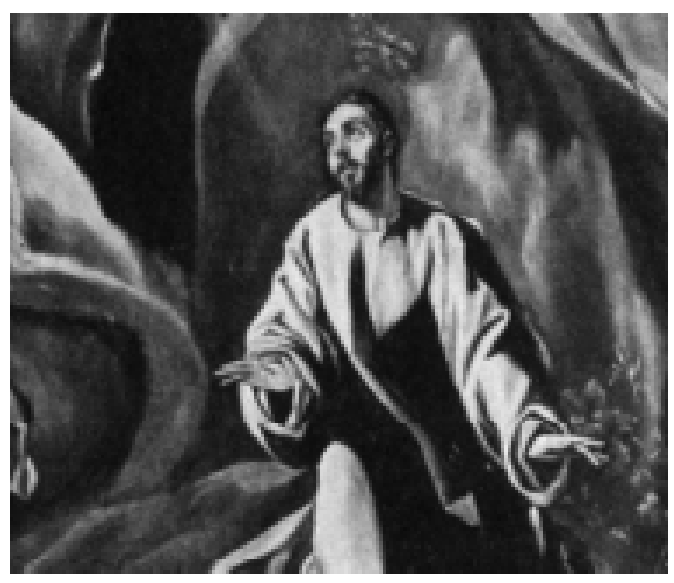

Através deste estudo, procuramos conhecer o significado que o fiel dá às noções de saúde, doença e cura diante do conteúdo vinculado pela Igreja Universal do Reino de Deus (IURD) a respeito de tal tema. Dessa forma, buscamos identificar práticas de saúde vinculadas à religião, em tal igreja, investigando as influências que a religião exerce na maneira como os fiéis buscam formas de tratamento para as doenças. Também objetivamos detectar estratégias de convencimento utilizadas pela igreja para inculcação de conteúdos religiosos relacionados à cura, relatando e analisando criticamente alterações ocorridas no estado de saúde dos fiéis após intervenções religiosas e buscando suas concepções sobre tais alterações.

\section{Método}

Foram utilizados dois métodos, baseados nas recomendações de aplicação da etnometodologia em Psicologia: observação participante associada à entrevista (Garfinkel, 1967; Sato \& Souza, 2001). A observação participante consistiu na coleta de dados através da participação do primeiro autor na vida do grupo ou organização, tendo como dados a serem observados as formas que as pessoas

\section{"...para o homem que imagina o seu futuro com base na sua experiência passada, "voltar ao seu normal" significa retomar uma atividade interrompida. Curar, então, seria "fazer voltar à norma uma função ou um organismo que dela se tinha afastado" \\ Canguilhem}


utilizam para dar sentido e, ao mesmo tempo, realizarem as suas ações de todos os dias (Becker, 1993). Nessa técnica, o observador, enquanto parte do contexto, estabelece uma relação face a face com os observados, o que inclui a realização de entrevistas etnográficas (Sato \& Souza, 2001; Yin, 1990). Nossa proposta aproximou-se de uma postura de pesquisa da etnometodologia que visa a, através de uma observação atenciosa e análise dos processos aplicados nas ações, criar dispositivos que permitam pôr em evidência as lógicas de proceder pelas quais os membros da instituição interpretam a realidade social.

"Essas doenças se pega com mau olhado ou por se ter o corpo aberto e passar numa encruzilhada.

Quando passa numa encruzilhada de um cemitério é pior

ainda. Se você ou alguém da sua

familia já foi num

centro espírita ficou com o corpo aberto".

Assim, houve a participação do pesquisador em seis cultos e outras atividades, como as correntes e sessões de aconselhamentos da igreja. $\mathrm{Na}$ "condição de um fiel", no sentido de participar das atividades desenvolvidas por estes, procurou registrar falas e comportamentos das pessoas. A aproximação foi feita a partir da apresentação de uma queixa do primeiro autor deste artigo, que justificava seu pedido de auxílio à igreja. $\bigcirc$ pesquisador começou a freqüentar os cultos e a conversar com o pastor e os fiéis. Além disso, foram realizadas quatro entrevistas, uma com o pastor, e três, com fiéis. As entrevistas eram abertas e tinham o objetivo de investigar possíveis causas das doenças e qual o tratamento para tais. As entrevistas foram realizadas na própria igreja, após os cultos, com consentimento verbal dos participantes. No entanto, estas não foram gravadas por restrição da igreja. Foram tomados cuidados éticos, não identificando os participantes, não os expondo a situações de risco e realizando a entrevista de forma voluntária.

Para analisar os dados coletados, optamos pela análise de conteúdo (Bardin,1979). Utilizamos, como técnica, a análise temática. Neste trabalho, os temas levantados foram as noções de saúde, doença e cura, presentes nos fiéis e pastores da igreja. Ainda para Minayo (1996), a análise de conteúdo articula a superfície dos textos descrita e analisada com os fatores que determinam suas características: variáveis psicossociais, contexto cultural, contexto e processo de produção da mensagem emitida pelo sujeito. Dessa forma, a análise de dados foi feita a partir da idéia de que se faz necessário complementar a informação de campo com aquela relativa a outras ordens sociais e buscar interpretações e explicações a partir de elementos externos à situação particular (Sato \& Souza, 2001).

\section{Resultados e Discusão}

Para trabalhar com os sentidos de saúde, doença e cura percebidos nos fiéis da IURD, optamos por investigar como unidades temáticas principais: as causas do adoecimento, a relação do "diabo" com a doença e o caminho da cura.

\section{As Causas do Adoecimento}

Na igreja, a doença, além de ser vista como um problema físico, que pode causar seqüelas e morte, tem um significado de como se dá a relação da pessoa doente com o Espírito Santo. Assim, o nãoadoecimento demonstra um certo grau de proteção ou bênção que o fiel tem, sugerindo a noção de corpo fechado. Segundo o pensamento iurdiano, aquele fiel batizado tem o corpo fechado para o mal, podendo até ser atacado, mas, se tiver a "verdadeira fé", não será atingido. Já as demais pessoas possuem o corpo aberto, e isso pode darse por vários motivos, como: ter freqüentado um centro espírita ou passar por uma encruzilhada. Uma fiel explicou:

"Essas doenças se pega com mau olhado ou por se ter o corpo aberto e passar numa encruzilhada. Quando passa numa encruzilhada de um cemitério é pior ainda. Se você ou alguém da sua família já foi num centro espírita ficou com o corpo aberto".

No confronto com o fato de que, naquela cidade, há muitas encruzilhadas e centros espíritas, temos a resposta de que é por isso que há muita gente doente. A causa das doenças também pode ser atribuída à submissão aos prazeres carnais, mas, principalmente, à procura por outras religiões, o que está diretamente ligado à noção de corpo aberto.

Por outro lado, podem surgir reinterpretações para episódios de doenças, principalmente quando atingem pastores. Nesses casos, a doença passa a ser vista como uma provação a ser enfrentada ou um ataque do demônio para fazer calar aquele que leva a palavra de Deus. A doença do pastor, então, seria "um mecanismo do inimigo" para atingir um forte opositor na "guerra santa". Adquirindo um sentido positivo, a doença se torna uma dádiva que reafirma a condição de eleito daquele atingido. "As noções de saúde e doença só se tornam inteligíveis nesse sistema de representações se articuladas com aquelas atribuídas ao pecado, ao castigo, à degeneração humana, por um lado, e à graça, ao merecimento, ao poder mediador do Espírito Santo e à onipotência de Deus, por outro" (Neves, 1984. p. 41).

Vem à tona a discussão proposta por Laplantine (1991) sobre os conceitos de doença-maldição e doença-punição. As causas das doenças, colocadas pela igreja, enquadram-se melhor na categoria de doença-punição, uma vez que estas são vistas como conseqüências provocadas pelo 
próprio indivíduo ou grupo. A doença seria a transgressão de uma lei. Dessa forma, a noção de reparação se torna possível a partir de um retorno a essas leis.

A igreja dá, dessa forma, o porquê das doenças, e não o como. Porém, ainda para Laplantine (1991), a questão do porquê se torna mais importante na medida em que é por esse caminho que respondemos à questão do sentido da doença, que acaba sendo um sentido metafísico. Ainda para esse autor, a tal busca procura uma culpa ou um bode expiatório, o que abre a possibilidade de reparação, como vemos nessa igreja.

Nos ensinamentos religiosos da IURD, a divisão entre corpo e alma não faz sentido, uma vez que o corpo é uma forma de manifestação do poder divino. O mundo carnal e o mundo espiritual estão, portanto, juntos, e são o mesmo, influenciando-se. Tal pensamento aproxima-se das noções psicossomáticas e de uma compreensão antipositivista, que une mente e corpo, atualmente aceita com facilidade nos centros urbanos e alvo de procura de muitas pessoas, como, por exemplo, a onda esotérica e holística, a medicina antroposófica etc. Consideramos que este é um dos aspectos que caracterizam a igreja como uma "religião urbana", pois tal pensamento é eminentemente típico da vida moderna das cidades.

Apesar de fazerem uma subdivisão entre doenças materiais e espirituais, os crentes sempre enfatizam o fato de que todas elas podem ter um componente espiritual coadjuvante. De certa forma, o fato de a causa das doenças também ser atribuída à submissão aos prazeres carnais remete a uma explicação tanto espiritual como biológica, que também aponta para a questão dos valores. Um exemplo visto por nós foi o testemunho de uma jovem de cerca de 20 anos que disse ter sido curada de um problema no útero que nem ela mesma sabia definir qual era. Nesse caso, a doença da moça foi encarada como uma punição espiritual pelo fato de estar se prostituindo, porém sem deixar de considerar que suas práticas sexuais contribuíram para um enfraquecimento biológico que a deixou mais suscetível, ou seja, os espíritos utilizaram uma situação carnal de fato para punir a sua alma.

\section{A Guerra Contra o Diabo}

Se a causa da doença é demoníaca, então faz-se necessário combatê-la. É com esse argumento que a igreja lança uma verdadeira guerra contra o diabo. Tal guerra fica mais explícita nos ataques aos cultos afros, porém também há um ataque contra a Igreja Católica (papa, culto a Maria,
Conferência Nacional dos Bispos do Brasil etc). Para os fiéis, umbanda, candomblé e kardecismo cultuam e abrigam o demônio. Dessa forma, a expansão da IURD mantém íntima relação com sua obra de libertação; assim, os exorcismos aparecem como uma prática que demonstra o poder de Cristo e a autoridade dos seus servos sobre os demônios. Para Edir Macedo (1998), fundador da IURD, a sua igreja foi criada para um trabalho especial: a libertação de pessoas endemoniadas.

Até os termos usados em sua "guerra santa" são os mesmos das guerras reais, como: soldados, batalhas, lutas, munição, perigo, resistência, castigo, destruição, vitória, derrotas etc. O bispo Edir Macedo (1998) diz que os demônios se apossam das pessoas das seguintes maneiras: por participação direta ou indireta em centros espíritas, hereditariedade, trabalhos ou despachos, maldade, envolvimento com pessoas que praticam o espiritismo, comidas sacrificadas a ídolos etc. Os endemoniados apresentam alguns sintomas, que seriam os dez sinais de possessão: nervosismo, dores de cabeça constantes, insônia, medo, desmaios ou ataques, desejo de suicídio, doenças cujas causas os médicos não descobrem (psicossomáticas, no conceito da IURD), visões de vultos ou audição de vozes, vícios e depressão (Mariano, 1995), ou seja, qualquer pessoa pode se sentir um possuído, pois, mais cedo ou mais tarde, experimentam um ou mais desses sintomas. Para combater as religiões mediúnicas, a IURD traz elementos dessas crenças para dentro dos seus cultos e doutrinas. A eficácia do adversário tende a ser legitimada, uma vez que o fiel deve crer que existe um inimigo real.

Os demônios são combatidos, são identificados pelos nomes que os pais e mães-de-santo utilizam, sendo que, para cada mal, é identificado um causador demoníaco: Tranca-Rua, Exu-Caveira, Pomba-Gira, Exu-Veludo, Maria-Bonita, PretoVelho, Maria-Conga etc.

Durante o ritual, os demônios são geralmente invocados e obrigados a confessar a culpa pelos males da vida do fiel; logo após, são humilhados e expulsos. O principal dia para o exorcismo é a sexta-feira, dia da reunião de libertação. Não por acaso esse dia foi escolhido, uma vez que, na umbanda, a sexta-feira é conhecida como o dia das giras e de exu, porém, em quase todos os dias, são realizados exorcismos durante as orações feitas pelo pastor.

As orações de exorcismo duram cerca de quinze minutos e são acompanhadas de todo um ritual, com música, gritos, imposição de mãos, imposição de bíblias, "sacolejos" etc. Geralmente, a preparação das sessões de exorcismo, como da 
corrente dos setenta pastores (também conhecida como reunião psicossomática), começa com uma música, em volume alto, acompanhada pelos fiéis. Tal reunião ocorre especialmente para a cura de doenças, a partir do exorcismo dos fiéis.

Na IURD, é costume separar os fiéis libertos (batizados) e não libertos, já que não podem, infinitamente, fazer exorcismos. O crente batizado não é passível de possessão, mas só de opressão e tentações. Dessa forma, um batizado que já foi exorcizado nunca mais precisará sê-lo novamente, enquanto um fiel não liberto pode passar pelo ritual diversas vezes. Durante a coleta de dados, o pesquisador foi exorcizado três vezes, uma delas sendo filmada para a rede Record de Televisão. Também foi presenciado o caso de uma fiel doente que todas as semanas era exorcizada. Segundo os pastores, no caso da fiel citada, mais de uma sessão foi necessária porque, como os seus sintomas não sumiam, era um sinal de que o demônio ainda estava no seu corpo. No nosso caso, não obtivemos nenhuma explicação, mas a lógica era a mesma, pois, durante três semanas, repetimos o ritual, demonstrando que os sintomas continuavam.

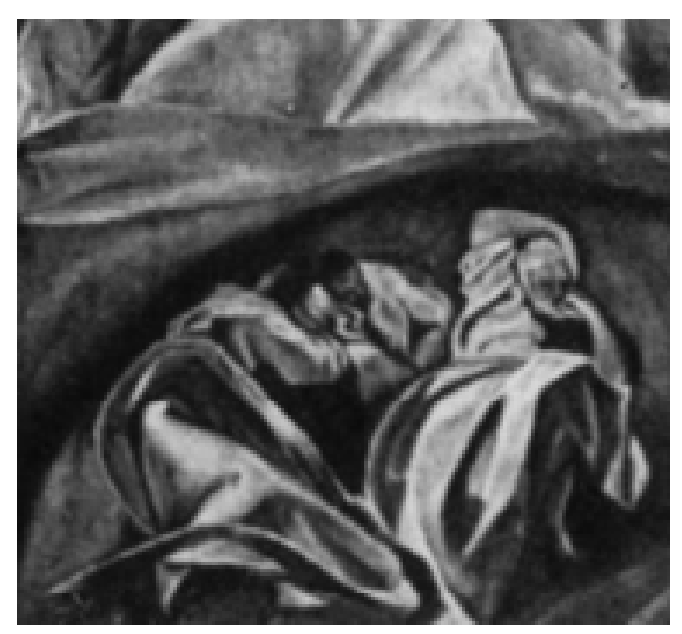

\section{O Caminho da Cura: Unções, Correntes, Bênçãos e Dízimo}

Apesar de admitir as causas concretas de algumas doenças, nem sempre se vêem como positivas as práticas da medicina oficial. Em alguns casos, o pastor costuma dizer que não resolve ir ao médico ou fazer exames, ou seja, participar dos rituais de cura da IURD e consultar médicos passam a ser atos quase excludentes, pois, para a lógica iurdiana, se o fiel crê que Deus quer salvá-lo, Ele fará isso, mesmo sem a ajuda médica. Quando nos apresentamos a um pastor para uma conversa sobre a doença que trazíamos (pedra nos rins), ouvimos o seguinte:
"Algumas doenças têm um caráter físico, estas são realmente do corpo, da carne; mas existe um tipo de doença que não é a da carne e que os médicos não têm cura, estas doenças são do espírito e é adquirida quando um espírito ruim, demônio, satanás... entra na nossa vida. A cura destas doenças também é espiritual e não adianta tomar remédio, porque os remédios agem na carne e este mal não está na carne. Para que esta cura se dê, é preciso que se faça muita oração, porque se tiramos o espírito ruim que causou este mal na vida, a doença também sai. Deus não criou o homem para que seus órgãos saiam do normal, então se seu rim está assim é porque há um demônio dentro de você, pois você abriu a porta para satanás entrar na sua vida, quando foi no centro espírita e também toda a sua família está contaminada pelo poder destes espíritos. O poder dos médicos tem limites e que eles próprios sabem disso! Não precisa ir mais no médico, ele não fez nada por você."

Tais idéias veiculadas pela IURD são opostas à encontrada em Neves (1984) em seu estudo sobre a Assembléia de Deus. Segundo essa autora, as práticas curativas da Assembléia de Deus, geralmente, estão agregadas ao tratamento médico, pois este é visto como um meio de o Espírito Santo agir e derramar suas bênçãos.

O fato de a IURD incitar a descrença na medicina oficial, muitas vezes, está ligado à questão do dinheiro. Em alguns testemunhos em que o fiel relata sua peregrinação pelo sistema de saúde e a compra de remédios, ou a busca por um médico particular, o pastor pergunta: Quanto você gastou? Sempre enfatizando que o gasto foi à toa e que seria melhor ter dado para a igreja. A explicação é a mesma utilizada no convencimento para dar o dízimo. Se o dinheiro for doado, o fiel será abençoado, caso contrário, todo o dinheiro que retiver será amaldiçoado.

É interessante perceber o que nos aponta Neves (1984) em relação à posição do crente doente que busca auxílio espiritual, já que, se participa dessa relação, é porque também se considera pecador:

"O doente é um ser ambíguo, pecador-crente, castigado ou abandonado pela graça divina. $O$ estabelecimento de relações reparadoras com os seres sobrenaturalizados prescreve a ação de intermediários, individualmente ou em grupo, cuja posição esteja mais claramente definida, cuja relação com Deus esteja mais socialmente reconhecida como positiva, sem ruptura" (Neves, 1984, p. 43).

Esse fato remete a uma discussão sobre a hierarquia da Igreja Universal. O pastor torna-se o intermediário, na medida em que possui poderes 
para retirar o demônio do corpo do doente em nome de Deus. A intervenção deste ocorre puramente num nível espiritual, sendo as alterações físicas decorrentes dessa ação. Qualquer explicação sobre o funcionamento do organismo passa a ser relegada a segundo plano. O conhecimento científico dá lugar, portanto, ao espiritual: o pastor sabe mais que o médico. A lógica de que Jesus é o médico dos médicos dá sentido ao poder do pastor, já que ele é um representante de Jesus e fala em nome deste.

Os rituais de cura podem ser realizados por um conjunto de crentes em forma de correntes. Assim, o poder do pastor não é a única forma de alcançar a graça. Em uma das atividades chamada "corrente dos setenta pastores", por exemplo, obreiros e demais fiéis fazem parte do ritual com imposição de mãos e orações individuais. Há, porém, uma diferença: quando o ritual é comandado pelo pastor, este pode fazê-lo sozinho, se assim o quiser. Já sem a presença deste, a cura só ocorre em grupo. Podemos perceber, então, que a fé que o fiel tem no Espírito Santo é inferior diante da hierarquia eclesiástica, sendo o pastor a figura que obtém o dom da cura. $O$ poder de um pastor sozinho equivale ao de 70 homens e mulheres.

Quando o tratamento medicamentoso não faz efeito, ou seja, quando os sintomas não desaparecem, o doente fica inseguro, o que é corroborado pela dificuldade de incorporar o significado dos atos médicos. O desengano médico atua como um estimulador para se recorrer ao sobrenatural. A noção de desengano transmite uma idéia de irreversibilidade, restando apenas a resignação que é oferecida pela religião. Na IURD, ao contrário de resignação, como em outras igrejas, o que é oferecido é uma nova possibilidade, pois lá "tudo é possível".

"Aqui se cura de doenças que os médicos não conseguem" (fiel).

"Nem em São Paulo me curei, onde também já fui em outra igreja de crente". (fiel).

"As doenças que o exame não deu nada, ou que o médico não pode curar, são curadas por Jesus aqui" (pastor).

"A palavra do médico é uma palavra de morte, de coisas ruins, mas na IURD a palavra é de vida e aqui encontramos a vida que os médicos desenganam" (pastor).

Para Neves (1984), o desengano pode ser uma incompreensão das explicações médicas. Quando o médico faz um encaminhamento para um especialista ou alerta para as graves conseqüências do abandono do tratamento, ou ainda, expõe os limites da medicação, tal fato pode ser compreendido como dificuldade para encontrar o caminho da cura. Já que o doente deseja uma resposta rápida para o alívio do seu sofrimento e não a obtém do médico, fica mais fácil aceitá-la quando ela surge em outro lugar - a igreja.

O desengano faz o doente buscar a cura milagrosa e, assim, aderir à igreja, uma vez que sua primeira tentativa foi recorrer à medicina oficial. Já para os fiéis adeptos da IURD, não é necessário chegar ao ponto do desengano, pois, como já dissemos, para estes, todas as doenças possuem seu componente espiritual. Porém, a ajuda médica é ainda tomada pelo fato de permanecerem resquícios de uma lógica biológica; por esse motivo, a própria IURD realiza campanhas de aplicação de flúor, verificação de pressão arterial, nível de glicemia etc

O ritual de cura configura-se como um ato terapêutico, em que se estabelece um regime a ser seguido e se faz um "diagnóstico", uma "prescrição" e um "prognóstico". A obtenção da graça da cura está diretamente ligada à subordinação do fiel às normas e aos ensinamentos da igreja. Ele deve participar das correntes rigorosamente, assim como faz um tratamento médico. O fiel deve ter determinação, como foi mencionado pelo pastor:

"As curas que acontecerão agora serão bem rápidas. Não precisa de orações longas, se tem fé, Jesus cura logo. Pra que ficar com blá, blá, blá? A gente precisa hoje mais de determinação do que de oração. Oração é amanhã, que é dia de buscar o Espírito Santo. Hoje, é só determinar na sua vida que o Senhor cura..."

A determinação aí exposta implica vários aspectos que dizem respeito ao seguimento de algumas regras. Uma delas é o pagamento do dízimo como imprescindível para se alcançar as bênçãos de Deus. A ênfase pode ser vista no episódio seguinte:

Depois da corrente dos 70, volta cada um para o seu lugar, e o pastor manda-os sentar porque agora vai começar a explicar como se tornar dizimista. Manda, então, que quem não é dizimista vá para a frente e leia um trecho da bíblia que fala da importância de doar a Deus o que tem. Explica que é melhor dar $10 \%$ e ter $90 \%$ abençoado do que ficar com dinheiro amaldiçoado. Diz: "se você ganha R\$100,00, é melhor dar R\$10,00 para Jesus e ter $R \$ 90,00$ que te trará graças. Se ganha $\mathrm{R} \$ 1000,00$, você tem que doar $\mathrm{R} \$ 100,00$. Se você é dona de casa e não tem salário, não tem problema, é só juntar cada centavinho que puder". O pastor explica que o dinheiro não é para ele e nem para a Igreja, é pra Jesus e suas obras. Por isso, não é preciso entregar na mão dele, deve-se dar

\section{"A reconstituição da história é uma montagem, cuja finalidade é confirmar no indivíduo o rótulo de criminoso".}

Rauter 
no envelope e pôr na "cesta" (referindo-se a um cesto de vime que fica no altar). Lê um trecho da bíblia que fala de um cesto onde se depositavam moedas para fazer ofertas. Começa a dizer que isso não é roubar o povo, como dizem, mas é o povo que não dá o dízimo que está roubando Deus. Começa a chamar os dizimistas de comprometidos e os não-dizimistas de ladrões.

\section{Considerações Finais}

As igrejas neopentecostais especializaram-se em prover soluções simbólicas para os mais variados problemas. Seu discurso fornece sentido, orienta e ajuda as pessoas a resolverem e contornarem suas aflições cotidianas. O diabo torna-se a causa principal de todos os males, sejam eles materiais, espirituais ou existenciais. A necessidade de retirálo, libertar-se, faz-se, então, fundamental.

O discurso neopentecostal faz sucesso porque o mal pregado por eles é vivido bem de perto por seus fiéis, seja no dia a dia (enfermidades, baixos salários, desemprego, brigas etc.) ou por conta de resquícios da sua religião anterior. Percebemos que o poder divino é, no entanto, limitado pelo livrearbítrio, que deixa uma parcela de responsabilidade para aquele que pratica os atos. Assim, ser pentecostal é muito mais do que passar a ter fé em algo em que antes não se acreditava, é necessário aderir a um sistema simbólico, uma escala de valores, mudar de comportamento, de estilo de vida e de visão de mundo.

Na IURD, o fiel tem a oportunidade do "novo nascimento". O poder de Jesus é exibido com a seguinte frase: "Minha vida mudou, sou outra pessoa". Ser crente passa a ser uma vantagem que, também, impõe certos sacrifícios, como a manutenção de uma conduta "correta" e manifestações contra o aborto e a homossexualidade.

Podemos enfatizar, como um dos fatores de diferenciação das práticas de saúde oficiais e religiosas, o caráter inclusivo destas últimas, contrário a uma exclusão social decorrente das outras, mais comum no sistema público. Na medicina oficial, o doente é tratado como um objeto, submetido a técnicas que excluem qualquer manifestação afetiva ou humana, ou como uma doença, muitas vezes, nociva à sociedade. Já nas igrejas, o fiel é acolhido como um "irmão em Deus", num ambiente onde os sentimentos de compaixão e ajuda predominam, e onde, ao invés de ser excluído de um grupo, o sujeito é amparado num novo grupo.

Além do mais, na igreja, o fiel encontra uma oportunidade de participação social, de conquista e de exercício de inclusão, que the foi negada por um mundo globalizado, individualista e competitivo. Mesmo em outras igrejas, o acolhimento não é tão grande como na IURD. Os cultos dos protestantes históricos, por exemplo, passaram a ser elitizados, supervalorizando a racionalidade, enquanto os cultos neopentecostais apelam, cada vez mais, para a emoção como forma de estabelecer pontes entre o palco e a platéia.

Devemos lembrar que os rituais de cura não são supervalorizados em relação a outras atividades de igreja. A cura da doença, assim como a obtenção de um emprego, a vida familiar organizada ou a vida financeira equilibrada, funciona como testemunho da fé e da proteção do Espírito Santo, fundamental para a expansão da igreja.

Concordamos com a seguinte idéia:

"Parece-nos que está em jogo uma concepção de vida que absorve, no plano simbólico, quase todos os atos e relações que o fiel tem que enfrentar no cotidiano ou aos quais se encontra referido" (Neves, 1984, p. 47).

O que ocorre é uma ampla visão de mundo, que abarca vários aspectos da vida do fiel, proporcionando uma capacidade de arranjos e rearranjos capaz de conferir significados próprios aos acontecimentos relatados. Assim, o uso do termo "doença psicossomática" adquire uma amplitude bem maior que a entendida pela Medicina e pela Psicologia contemporâneas. Tal termo passa a ser usado com o fim de, mais uma vez, ampliar o campo de significados possíveis para os fatos, já que o tema doença privilegia tais concepções na medida em que é, de certa forma, mitológico, conforme já expusemos na introdução.

Como nos diz Neves (1984),

"A visão religiosa não pode ser entendida apenas ao nível de sua atualização institucional - a igreja - mas ela perpassa vários domínios sociais, constituindo uma "teoria", uma forma de conhecer e conceber o mundo que absorve grande parte dos atos cotidianos dos devotos" (p. 50).

Percebemos que, assim como a IURD faz um rearranjo a fim de procurar explicações para a causa das doenças, ela também usa tal estratégia para explicar os casos de fracasso ou contradições, como quando a doença atinge o pastor. Tais análises levam, cada vez mais, a pensar que a ordem simbólica desempenha um papel ativo no ordenamento do mundo social. 
Elder Cerqueira-Santos, Sílvia Helena Koller \& Maria Teresa Lisboa Nobre Pereira Instituto de Psicologia, R. Ramiro Barcelos, $n^{\circ}$ 2600/104 - CEP 90035-003, Porto Alegre/RS.

E-mail: eldercerqueira@yahoo.com.br

ALVES, R. A Empresa da Cura Divina: um Fenômeno Religioso. In E. E. Vale \& J. J. Queiroz (org.). A Cultura do Povo. São Paulo: Cortez e Moraes \& EDUC, 1979, pp.111-117.

BARDIN, L. Análise de Conteúdo. (Trad. L. A. Reto \& A. Pinheiro). São Paulo: Edições 70/ Livraria Martins Fontes, 1979 (original publicado em 1977).

BECKER, H. Métodos de Pesquisa em Ciências Sociais. São Paulo: HUCITEC, 1993.

BOURDIEU, P. Coisas Ditas. São Paulo: Brasiliense, 1987.

CANGUILHEM, G. O Normal e o Patológico. Rio de Janeiro: ForenseUniversitária, 1979.

COELHO, M. T. A. \& ALMEIDA, N. Normal-Patológico, Saúde-Doença: Revistando Canguilhem. Physis - Revista de Saúde Coletiva, 9(1). Rio de Janeiro: UERJ/IMS, 1999.

CONCONE, M. H. V. B. Umbanda, uma Religião Brasileira. São Paulo: CER/USP, EDUSP, 1987

FISH, J. M. Placebo Terapia: a Fé no Processo de Cura. Campinas,SP: Papirus, 1998.

FOUCAULT, M. Microfísica do Poder. Rio de Janeiro: Graal, 1979

GAARDER, J. O Livro das Religiões. São Paulo: Cia das Letras, 2000.

GARFINKEL, H. Studies in Ethnomethodology. Cambridge, UK: Polity Press, 1967.

GUARESCHI, P. A. "Sem Dinheiro não há Salvação": Ancorando o Bem e o Mal Entre os Neopentecostais. In P. A. Guareschi \& S Jovchelovich (org.), Textos em Representações Sociais. Petrópolis, RJ: Vozes, 1995, pp.191-225

HOUTART, F. Sociologia de la Religión. Managua: Nicaragua, 1994

LAPLANTINE, F. Antropologia da Doença. São Paulo: Martins Fontes 1991.

\section{$\overline{\text { Brasiliense, } 1995 .}$}

Aprender Antropologia. São Paulo: Editora

LAPLANTINE, F. \& RABEYRON, P. Medicinas Paralelas. São Paulo: Brasiliense, 1991.

LEVI-STRAUSS, C. Antropologia Estrutural. Rio de Janeiro: Tempo Brasileiro, 1970.

MACEDO, E. Orixás, Caboclos \& Guias: Deuses ou Demônios. Rio de Janeiro: Universal, 1998.

MARIANO, R. Neopentecostais. Dissertação de Mestrado não publicada. Universidade de São Paulo, São Paulo, 1995.

NEVES, D. P. As Curas Milagrosas e a Idealização da Ordem Social. Niterói: UFF, 1984.

PEREIRA, M. T. L. N. Por uma Psicologia de Corpo e Alma. Dissertação de Mestrado não publicada. Núcleo de Pós-Graduação e Pesquisa em Ciências Sociais, Universidade Federal de Sergipe. Aracaju, SE, 1997.

PRANDI, R. A Religião do Planeta Global. In A. P. Oro (org.). Globalização e Religião. Petrópolis: Vozes, 1997.

QUINTANA, A. M. A Ciência da Benzedura: Mau-olhado, Simpatias e uma Pitada de Psicanálise. Bauru-SP: EDUNUSC, 1999.

Revista Isto É. (28 de maio de 1997). O Milagre da Cura. World Wide Web: http://www.istoe.com.br, acessado em 04/06/2002.

SATO L. \& SOUZA. M. P. R. Contribuindo Para Desvelar a Complexidade do Cotidiano Através da Pesquisa Etnográfica em Psicologia. Psicologia USP, 12(2). Versão eletrônica acessado em uww.scielo.br em 04/06/2002.

YIN, R. K. Case Study Research: Design and Methods. Beverly Hills: Sage, 1990. 